\title{
LOS MUSEOS PEDAGÓGICOS EN ESPAÑA. ENTRE LA MEMORIA Y LA CREATIVIDAD
}

por Pablo Álvarez Domínguez (coord.). Gijón-Sevilla, Ediciones Trea y Editorial Universidad de Sevilla, 2016, 260 páginas. ISBN: 978-84-9704-957-3 (Ediciones Trea) 978-84-472-1859-2 (Editorial Universidad de Sevilla).

Desde que en 2004 se creara la Sociedad Española para el estudio del Patrimonio Histórico-Educativo (SEPHE) por el profesor Julio Ruiz Berrio, el trabajo de colaboración y promoción de los espacios histórico-educativos creció, y el estudio de la museología y museografía en este ámbito desarrolló una literatura abundante que hoy día ya constituye una línea propia de investigación dentro de la historia de la educación.

Posiblemente, la obra coordinada por Pablo Álvarez Domínguez, sea uno de los resultados más importantes de la mencionada sociedad. Con la llegada de Los Museos Pedagógicos en España. Entre la memoria y la creatividad, disponemos por fin de un compendio o catálogo detenido y profundo de una importante selección de los museos histórico-educativos más representativos de la geografía española, nacidos todos ellos al albor de la transición democrática y bajo el legado del desaparecido Museo Pedagógico Nacional.

A modo de diario de historias, este compendio realiza un trayecto por prácticamente todas las comunidades autónomas. Dentro de cada una, las personas encargadas de idear y dirigir cada museo realizan un repaso por la historia propia de cada espacio y sus particularidades. Quizá sea, precisamente, el contraste y la diversidad de los museos en cuanto a su naturaleza y función (expositiva, archivística, incluso teatral o interpretativa), el principal activo que aporta la presente obra. Los museos pedagógicos españoles no son uniformes ni homogéneos, si bien todos ellos, a modo de denominador común, cumplen con los objetivos de la 
materialización, visibilización, valoración y transferencia educativa y socio-cultural del patrimonio histórico-educativo. ${ }^{1}$

En definitiva, cada museo destaca por algo. Un buen ejemplo de la diversidad museística lo tiene Andalucía con dos museos con improntas diferentes. El museo pedagógico de la Universidad de Sevilla destaca por su teatralidad, por su carácter interpretativo. Un espacio que pone de relieve la necesidad de contar con testimonios e historias propias, pues «los objetos museísticos hablan si son interpretados a través de los recuerdos que suscitan en quien los ve y los toca, en quien les da un argumento». ${ }^{2}$ No muy lejos, su homólogo en la Universidad de Huelva se erige como un museo de la escolaridad, ${ }^{3}$ que destaca por la multitud de actividades y proyectos que se han realizado en él y que se idearon, así como por las iniciativas referidas a la educación del futuro. Además, la concepción y cabida que da este museo del patrimonio inmaterial a través del material y el análisis y gestión de los silencios mediante los testimonios, refleja una alternativa que ubica al museo pedagógico como un espacio para toda la sociedad, desde colegios a turistas, pasando por asociaciones de personas con alzhéimer y el propio alumnado universitario.

Por su parte, de Aragón y su museo pedagógico cabe destacar, que pese a sus pocos años de vida haya trazado un proyecto heterogéneo que aúna muchas de las múltiples concepciones que puede adoptar un espacio histórico-educativo nacido del interés gubernamental de la comunidad autónoma. Mención especial merecen las actividades y talleres que desarrolla, sobre temas como la historia más personal de Joaquín Costa o la imprenta de Freinet en Aragón, llevadas a cabo de forma cíclica; es decir, empezando y terminando dichas historias dentro del propio museo.

Con la misma edad, y nacido también del interés del gobierno regional, el Centro de Recursos, Interpretación y Estudios de la Escuela (CRIEME) de Cantabria ha comenzado una trayectoria que destaca por

\footnotetext{
${ }^{1}$ Pablo Álvarez Domínguez, Los Museos Pedagógicos en España. Entre la memoria y la creatividad (Gijón-Sevilla: Ediciones Trea y Editorial Universidad de Sevilla, 2016), 14.

2 Pablo Álvarez Domínguez, Marina Núñez Gil y M. a José Rebollo Espinosa, «El Museo Pedagógico de la Facultad de Ciencias de la Educación de la Universidad de Sevilla: una obra en tres actos», en Los Museos Pedagógicos en España. Entre la memoria y la creatividad, coord. Pablo Álvarez Domínguez (Gijón-Sevilla: Ediciones Trea y Editorial Universidad de Sevilla, 2016), 40.

3 Manuel Reyes Santana, «El Museo Pedagógico de la Universidad de Huelva», en Los Museos Pedagógicos en España. Entre la memoria y la creatividad, 53.
} 
sus publicaciones, como la revista Cabás, y sus proyectos, como Escuelas olvidadas, basado en la recuperación de la memoria de centros educativos que ya no existen, y cuya labor, fundamentalmente a través de testimonios, es de un interés extrapolable a cualquier otra región. Cabe señalar también, de esta institución, el interés por la digitalización de todos sus recursos y bases de datos.

Con una larga historia, el Museo Pedagógico y del Niño de Albacete (MUNI), en Castilla-La Mancha, refleja la trayectoria y vicisitudes a las que hace frente un museo histórico-educativo. Como se ha visto en varios ejemplos, y se verá posteriormente, el continuo crecimiento de estos espacios por la ampliación de sus fondos, hace que a menudo sus emplazamientos sean insuficientes para acoger una institución de tan marcado carácter y uso social. Con un pasado de continuos cambios e incertidumbres, el MUNI supone un buen ejemplo de complejidad y dificultad en la que muchos de los museos histórico-educativos se sentirán fácilmente reflejados. No en vano el actual MUNI se emplaza en dos edificios de grandes dimensiones donde se da cabida a multitud de salas donde poder celebrar exposiciones, seminarios y talleres para un ya asentado e histórico museo pedagógico.

Al igual que ocurriera con Andalucía, Castilla y León es otra comunidad autónoma con varios ejemplos de museos histórico-educativos. Asentado sobre una tierra testigo de la escolarización castellana y soriana, el Centro Internacional de la Cultura Escolar (CEINCE) se ubica en un enclave rural que invita a la reflexión y la sostenibilidad desde hace once años. Convertido en un centro de diálogo y conversación, ha actuado como cruce de caminos para múltiples profesionales e investigadores nacionales e internacionales, y está vinculado a más de una veintena de instituciones. Nacido con el apoyo europeo y latinoamericano, el CEINCE, al igual que ocurriera con el museo pedagógico de la Universidad de Huelva, tiene la mirada puesta en el pasado y el presente, pero también en el futuro, rompiendo con la concepción de que estos espacios son meros conservadores y expositores de la escuela pretérita.

$\mathrm{Al}$ otro lado de la región castellanoleonesa, se encuentra ubicado en la ciudad de Zamora el Centro-Museo Pedagógico de la Universidad de Salamanca (CEMUPE). Creado tan solo un año más tarde que el CEINCE, el CEMUPE centra su actividad en torno a la infancia y la escuela a través 
del estudio de la cultura material, escrita y oral. De entre las fuentes y actividades más destacadas se encuentra el uso del cuaderno escolar, un material que consigue «establecer puentes entre la escuela de antes y la de ahora para conocer dónde y cómo se educaron generaciones anteriores a las nuestras». ${ }^{4}$ Otra fuente que trae consigo una práctica educativa de gran interés es la correspondencia tutorial entre maestros jubilados y estudiantes universitarios. Con los testimonios de quienes han dedicado por entero su vida a la enseñanza y la disposición al aprendizaje de quienes la tienen por delante, se produce un diálogo significativo y se consigue además una fuente de naturaleza oral sobre la experiencia educativa de maestros veteranos.

El tercer espacio histórico-educativo de Castilla y León es el Museo Pedagógico de la localidad segoviana de Otones de Benjumea. Nacido de la exitosa exposición La última escuela de Otones de Benjumea en el año 1996, se trata de una muestra de cooperación y colectivismo entre personas interesadas por la historia local de sus municipios. Su colección, dividida en varias salas y aulas de época, es objeto de interés por parte de ciudades y pueblos de la región. Actualmente se encuentra en un proceso de apertura a las nuevas tecnologías para potenciar la investigación y difusión de sus fondos.

Señalaba Escolano Benito, en su capítulo sobre el CEINCE, que uno de los grandes desafíos actuales y del futuro es el impacto del giro digital y las tecnologías ${ }^{5}$ y, efectivamente, esta corriente ha llegado ya a los museos pedagógicos. Muestra de ello es el Museo Virtual de Pedagogía de la Universidad de Vic (MUVIP), en Cataluña. Bajo los principios de universalidad y accesibilidad, la naturaleza virtual de este espacio permite un contacto directo con el patrimonio del museo, especialmente útil para personas que tienen dificultades de desplazamiento. Este soporte le permite tener registros documentales, elementos gráficos y audiovisuales de forma accesible, de tal modo que todo el material siga en manos de sus propietarios, permitiendo estos su difusión digital a investigadores,

\footnotetext{
${ }^{4}$ Bienvenido Martín Fraile y M. ${ }^{a}$ Isabel Ramos Ruiz, "Centro Museo Pedagógico de la Universidad de Salamanca (CEMUPE)», en Los Museos Pedagógicos en España. Entre la memoria y la creatividad, 124. ${ }^{5}$ Agustín Escolano Benito, «El Centro Internacional de la Cultura Escolar», en Los Museos Pedagógicos en España. Entre la memoria y la creatividad, 108.
} 
alumnado, instituciones educativas, y en definitiva a cualquier persona interesada con acceso a internet.

Otro ejemplo de museo virtual se ubica en Murcia, con el Museo Virtual de Historia de la Educación (MUVHE), que ofrece múltiples exposiciones e itinerarios posibles. La peculiaridad de este espacio virtual es su complementariedad con el Centro de Estudios sobre la Memoria Educativa (CEME), que supone un punto de convergencia transversal y multidisciplinar en la Universidad de Murcia. En definitiva, MUVHE y CEME aúnan las dos modalidades de acceso (virtual y presencial respectivamente), uniendo asimismo a profesionales de múltiples áreas y disciplinas, convirtiéndose, gracias a su interacción, en un museo/laboratorio de historia de la educación.

Esta denominación es también adoptada por el Museo/Laboratorio de Historia de la Educación «Manuel Bartolomé Cossío» de la Facultad de Educación de la Universidad Complutense de Madrid. Creado en 1991, su denominación da a este espacio un cariz de indagación, experimentación y aprendizaje. Junto a estas finalidades, este espacio histórico-educativo se erige como centro de encuentro para múltiples culturas de la capital y de la propia universidad, fiel reflejo de una sociedad diversa y cada vez más plural, si bien no pierde el objetivo básico de conservación, custodia y análisis de patrimonio. De sus fondos, destaca el «Fondo Romero Marín», con casi novecientas memorias de prácticas de estudiantes de pedagogía fechadas entre los años cincuenta y principios de los setenta, así como con un vasto acervo de manuales escolares, y una segunda sala dedicada casi exclusivamente a una gran cantidad de materiales de ciencias experimentales.

No obstante, también existen espacios educativos que abarcan diferentes denominaciones, como es el caso del Seminari-Museu d'Historia de l'Escola, de la Universidad de Valencia. Con una estructura articulada en torno a un aula-seminario y una exposición permanente en la Facultad de Educación de la mencionada universidad, y un aula-museo en la ciudad valenciana de Ontinyent, este complejo museístico tiene, aparte de unos fondos y localizaciones considerables, una aspiración basada en la creación de una red de centros y espacios histórico-educativos que vertebre toda la Comunidad Valenciana, y que dote de fuerza a una institución o museo pedagógico ampliamente representada por su territorio. 
La creación de redes regionales es también un objetivo en Galicia y su Museo Pedagóxico de Galicia (MUPEGA). Con unas aspiraciones históricas que se remontan al año 1898, esta región siempre ha tenido en mente la creación es un espacio museístico de la educación y su historia. Con la llegada de la Transición, en varios centros e instituciones se sucedieron múltiples exposiciones hasta que fuera creado en 2001 con unas amplias instalaciones que aglutinan la documentación y conservación del patrimonio histórico-educativo, así como exposiciones temporales, itinerantes y la celebración de jornadas o cursos entre otras muchas actividades.

Abarcando también todo el territorio regional, se encuentra el Arxiu i Museu de l'Educació de les Illes Balears (AMEIB) que, al igual que el MUPEGA, fue creado por el gobierno autonómico en el año 2001. Articulado en archivo, museo y biblioteca, este centro se caracteriza por unos dilatados fondos de manuscritos, mobiliario y material escolar entre otros muchos, con una constante ampliación de su muestra y una gran actividad de difusión, donde destacan sus relaciones de colaboración con otras instituciones.

El proyecto del otro archipiélago, el canario, a través de su Museo de la Educación de la Universidad de La Laguna (MEDULL), hace especial énfasis en el estudio y seguimiento de la historia de las escuelas autonómicas, los saberes escolares y la figura del profesorado. Con un emplazamiento a esperas de ser ampliado, el museo canario destaca por su exposición permanente, consistente en un recorrido por las principales aulas históricas, así como por la minuciosa catalogación de todos sus fondos.

El último museo de la selección de esta obra se ubica en el País Vasco. El Museo de la Educación de la Universidad del País Vasco (HM-EHU por sus siglas en euskera), es de reciente creación. Fundado en 2014, recoge el legado del centro de documentación sobre historia de la educación en el País Vasco, y consta de una variada muestra de fuentes documentales y patrimoniales, destacando los cuadernos y memorias escolares. El HM-EHU cuenta con cuatro espacios, dedicados al euskera, a la recreación de dos aulas - una del franquismo y otra de los años setenta-, a las políticas e instituciones vascas y a la enseñanza y el aprendizaje. Lleva a cabo, además, una importante labor investigadora encabezada por el grupo de investigación Garaian. 
En total, diecisiete espacios que custodian, conservan, difunden y amplían el patrimonio histórico-educativo en toda la geografía española. Espacios con diferente denominación pero con el mismo objetivo. Espacios con diferentes modalidades, presenciales y físicos, dependientes de universidades, gubernamentales o de asociaciones, con espacios más o menos amplios, algunos de ellos incluso con varios centros. En definitiva, una red de museos que la Sociedad Española para el Estudio del Patrimonio Histórico-Educativo aúna en un volumen que recoge, en líneas generales, lo más significativo de cada uno.

Con esta muestra, España puede presumir de ser uno de los países con más representación de estos espacios. Con un diez por ciento del total mundial, nuestro país resulta puntero en materia museístico-educativa, con planteamientos que abandonan la concepción del museo pedagógico como mero conservador patrimonial, y abren las puertas a nuevas formas de difusión, de colaboración institucional e investigación. Los museos pedagógicos en España se dejan tocar por sus visitantes, y abren además una línea social que entra en contacto con personas con diversidad funcional, personas con trastornos del espectro autista o con alzhéimer, y ofrece una nueva visión al patrimonio histórico-educativo como evocador de recuerdos y objeto de múltiples historias de vida.

Carlos Sanz Simón Alumno de Doctorado Universidad Complutense de Madrid (UCM) csa02@ucm.es 